\title{
ANÁLISE TÉCNICA E ECONÔMICA DA APLICAÇÃO FOLIAR DE POLIFOSFATO DE AMÔNIO NA CULTURA DO MILHO
}

\author{
FABIANO PACENTCHUK ${ }^{1}$, ITACIR ELOI SANDINI ${ }^{1}$ e MARGARETE KIMIE FALBO ${ }^{1}$
}

\author{
${ }^{1}$ Universidade Estadual do Centro-Oeste - UNICENTRO/Campus Cedeteg \\ Rua Simeão Camargo Varela de Sá, 03 - Vila Carli/CEP 85040-080 \\ fabianopacentchuk@gmail.com,isandini@hotmail.com,margaretefalbo@hotmail.com
}

Revista Brasileira de Milho e Sorgo, v.15, n.3, p. 377-385, 2016

\begin{abstract}
RESUMO - O objetivo deste trabalho foi realizar uma análise técnica e econômica da aplicação foliar de polifosfato de amônio na cultura do milho, bem como seus efeitos nos componentes de produtividade da cultura. O delineamento experimental utilizado foi o de blocos casualizados com quatro repetições em arranjo fatorial $3 \times 3 \times 4$. Sendo, 3 safras agrícolas, 3 estádios de aplicação (V13, VT e o parcelamento no V13 + VT) e 4 doses de polisfosfato de amônio (0, 5,10 e $\left.15 \mathrm{~L} \mathrm{ha}^{-1}\right)$. Houve influência positiva das doses de polifosfato de amônio estudadas na produtividade da cultura do milho. O máximo incremento de produtividade foi obtido com a aplicação de 5,08 e 1,51 kg ha-1 de $\mathrm{P}_{2} \mathrm{O}_{5}$ e $\mathrm{N}_{\text {, }}$ respectivamente, o que corresponde a $9,54 \mathrm{~L} \mathrm{ha}^{-1}$ de polisfosfato de amônio. A resposta positiva independe do ano e do estádio de aplicação. O uso de polisfosfato de amônio apresenta viabilidade econômica sendo que o incremento de produtividade foi de $534 \mathrm{~kg} \mathrm{ha}^{-1}$, foi obtido por meio da aplicação de 7,14 $\mathrm{L} \mathrm{ha}^{-1}$ de polisfosfato de amônio. A aplicação do polifosfato de amônio não influenciou estatisticamente os componentes de produtividade estudados.
\end{abstract}

Palavras-chave: Adubação foliar, fósforo, Zea mays.

\section{TECHNICAL AND ECONOMIC ANALYSIS OF FOLIAR APPLICATION OF AMMONIUM POLYPHOSPHATE IN MAIZE}

\begin{abstract}
The aim of this study was a technical and economic analysis of foliar application of ammonium polyphosphate in maize and its effect on crop yield components. The experimental design was a randomized block with four replications in a factorial arrangement $3 \times 3 \times 4$, comprising 3 crop seasons, 3 growth stages (V13, VT and the splitting in V13 + VT) and 4 doses of ammonium polyphosphate $\left(0,5,10\right.$ and $\left.15 \mathrm{~L} \mathrm{ha}^{-1}\right)$. There was a positive effect of doses of ammonium polyphosphate studied on maize yield. The maximum increase in yield was obtained with the application of 5.08 and $1.51 \mathrm{~kg} \mathrm{ha}^{-1}$ of $\mathrm{P}_{2} \mathrm{O}_{5}$ and $\mathrm{N}$, respectively, corresponding to $9.54 \mathrm{~L} \mathrm{ha}^{-1}$ of ammonium polyphosphate. The positive response was independent of the year and the growth stages. The use of ammonium polyphosphate presents economic viability and the increase in yield was $534 \mathrm{~kg} \mathrm{ha}^{-1}$ by applying $7.14 \mathrm{~L}$ $\mathrm{ha}^{-1}$ of ammonium polyphosphate. The application of ammonium polyphosphate not statistically affected the yield components studied.
\end{abstract}

Keywords: foliar fertilization, phosphorus, Zea mays. 
O milho (Zea mays L.) é uma importante cultura para a agricultura brasileira e pode ser cultivada em todas as regiões do país. Diante de um cenário onde se busca aumentar a produtividade e de certa forma diminuir a abertura de novas áreas, é importante proporcionar condições para o pleno desenvolvimento das culturas. Dentre todos os fatores para obtenção de altas produtividades, destaca-se o fornecimento de nutrientes.

Tratando-se dos macronutrientes primários, embora a necessidade de fósforo $(\mathrm{P})$ seja menor que as quantidades de potássio $(\mathrm{K})$ e de nitrogênio $(\mathrm{N})$, sua aplicação nas culturas ocorre em doses iguais ou superiores a esses dois elementos. Isso se deve à elevada taxa de fixação do $\mathrm{P}$ em solos tropicais, que são caracterizados pelo elevado grau de intemperismo e pelos baixos teores de fósforo na forma disponível às plantas (Pelá et al., 2009).

O P é o nutriente que mais onera os custos de produção agrícola (Broggi et al., 2014) devido à carência generalizada deste elemento nas áreas destinadas para a agricultura. Assim, dentre outros fatores, para obtenção de elevadas produtividades, faz-se necessário o manejo adequado da fertilidade do solo (Oliveira et al., 2013).

O fósforo é essencial no metabolismo das plantas. A sua baixa disponibilidade na fase inicial do ciclo vegetativo pode causar restrições ao desenvolvimento das plantas (Souto et al., 2009). Além disto, o $\mathrm{P}$ é um componente vital no processo de conversão da energia luminosa em alimentos, fibras e óleos pelas plantas.

A aplicação de P no solo representa um custo elevado, já que grande parte dele fica retido pelos processos de fixação e adsorção do fósforo em solução nas formas iônicas com os elementos químicos ferro, alumínio e cálcio (Novais et al., 2007).
A aplicação foliar do fósforo é uma estratégia para minimizar os problemas mencionados, pois esta técnica, dentre outros problemas, evita a fixação do $\mathrm{P}$ pelo solo. Sabe-se também que a aplicação de $\mathrm{P}$ foliar na fase vegetativa, como efeito estimulante ao crescimento da planta e com consequente aumento da absorção de nutrientes do solo, é uma estratégia de manejo importante para as culturas de interesse agrícola (Cobucci et al., 2010).

Taiz \& Zeiger (2009) relataram que maioria das plantas consegue absorver nutrientes minerais aplicados nas folhas por aspersão; desta forma, a reposição dos nutrientes nas folhas, através de adubação foliar, poderia manter a taxa de fotossíntese por um tempo maior, o que possivelmente refletiria em maior produção de grãos (Rezende et al., 2005).

$O$ fósforo possui acentuada mobilidade no floema dos vegetais, sendo translocado por este para as demais partes da planta (Fancelli, 2010), fato que favorece a aplicação via foliar deste nutriente. Na planta, o P é um elemento móvel, facilmente redistribuído entre os órgãos, das folhas velhas para as novas, para os frutos e sementes, característica importante para a adubação foliar (Silva, 2006).

No início do estádio reprodutivo até a maturação, a atividade radicular e a absorção de $\mathrm{P}$ do solo diminuem ao mesmo tempo em que há grande translocação do nutriente das folhas para as sementes em formação; logo, a adubação foliar de P na cultura do milho apresenta fundamentos científicos.

Segundo Meira et al. (2009), o N é o nutriente mineral exigido em maior quantidade pelo milho e via de regra proporciona os maiores efeitos na produtividade de grãos, sendo, em geral, necessário o uso de adubação nitrogenada via foliar para complementar a quantidade fornecida pelo solo, visando a obtenção de produtividades elevadas. 
Além das contribuições individuais de $\mathrm{N}$ e $\mathrm{P}$ para as culturas, é importante observar o comportamento destes nutrientes quando aplicados em conjunto. Nannetti (2001) salienta que há efeito sinérgico entre o uso de nitrogênio e o fósforo. A deficiência de $P$ pode induzir a de $\mathrm{N}$, principalmente pela redução nas taxas de absorção de nitrato (Lee et al., 1992). Assim, essa relação entre $\mathrm{N}$ e P poderá levar a situações onde, mesmo quando o fornecimento de P está adequado, as produtividades serão baixas em função da deficiência de $\mathrm{N}$; o contrário também poderá ser observado.

Tendo em vista as limitações da aplicação de P no solo, a necessidade de aumentar a produtividade das culturas, a resposta das culturas à aplicação foliar de $\mathrm{P}$ e a relação entre $\mathrm{N}$ e $\mathrm{P}$, este trabalho objetivou realizar uma análise técnica e econômica da aplicação foliar de polifosfato de amônio na cultura do milho, bem como seus efeitos nos componentes de produtividade da cultura.

\section{Material e Métodos}

Os estudos foram realizados na região Centro-Sul do estado do Paraná, no município de Candói. O mesmo ensaio foi realizado nas safras agrícolas 2013/14, 2014/15 e 2015/16 na fazenda Modelo.

O clima da região é classificado como subtropical mesotérmico úmido sem estações secas e com verões amenos. Durante o período experimental (das três safras avaliadas), a temperatura máxima média, a temperatura mínima média e a precipitação pluviométrica foram similares às médias históricas; portanto, não foram fatores restritivos à cultura do milho. Não houve registros da ocorrência de eventos adversos, como ventos fortes e granizos. As áreas utiliza- das nos experimentos possuem solo do tipo Latossolo Bruno distroférrico Típico.

As informações de cada safra estão demonstradas na Tabela 1. As áreas estão sendo manejadas no sistema de plantio direto há mais de 10 anos e, no inverno que antecedeu a implantação dos experimentos, foi cultivada aveia preta. O delineamento experimental utilizado foi o de blocos casualizados com quatro repetições em arranjo fatorial $3 \times 3 \times 4$. Sendo três safras agrícolas, três diferentes estádios de aplicação (V13, VT e o parcelamento no V13 + VT) e quatro diferentes doses de polifosfato de amônio (0, 5, 10 e 15 $\mathrm{L} \mathrm{ha}^{-1}$ ). A escolha do híbrido a ser utilizado para cada safra (demonstrado na Tabela 1) seguiu o critério de representatividade da área na região; portanto, o híbrido com maior área semeada naquela determinada safra foi escolhido para ser semeado no ensaio.

As aplicações do $\mathrm{P}$ e do $\mathrm{N}$ foram realizadas por meio de um pulverizador costal elétrico com pressão constante, resultando numa taxa de aplicação de 160 $\mathrm{L} \mathrm{ha}^{-1}$. A fonte de fósforo e nitrogênio utilizada para todos os ensaios foi o polifosfato de amônio, presente no produto comercial FreeFós, o qual contém 37\% de $\mathrm{P}_{2} \mathrm{O}_{5}$ e $11 \%$ de $\mathrm{N} \mathrm{em} \mathrm{p} / \mathrm{p}$, com densidade de $1,44 \mathrm{~g} \mathrm{~cm}^{-3}$.

As avaliações realizadas foram altura de planta, altura de inserção de espiga, número de fileiras por espiga, número de grãos por fileira, número de grãos por espiga, grãos ardidos, massa de 1.000 grãos (MMG) e produtividade.

Antes da colheita, com o auxílio de uma régua graduada, realizaram-se as medições de altura de inserção da primeira espiga e altura final de planta. Para isso, foram medidas três plantas escolhidas aleatoriamente a cada parcela.

Para produtividade, colheram-se as espigas da área útil da parcela. Estas foram trilhadas, pesadas e tiveram medida a umidade. Posteriormente, realizou- 
Tabela 1. Informações das safras estudadas no ensaio. Candói, PR - 2016.

\begin{tabular}{|c|c|c|c|}
\hline \multirow{2}{*}{ Atividade } & \multicolumn{3}{|c|}{ Safra } \\
\hline & $2013 / 14$ & $2014 / 15$ & $2015 / 16$ \\
\hline Semeadura & $12 / 10 / 2013$ & $14 / 09 / 2014$ & $24 / 09 / 2015$ \\
\hline Híbrido & AS 1656 PRO II & DKB 290 PRO III & AS 1656 PRO III \\
\hline Espaçamento (m) & 0,8 & 0,425 & 0,425 \\
\hline População (plantas ha $\left.{ }^{-1}\right)$ & 85.000 & 85.000 & 85.000 \\
\hline \multicolumn{4}{|l|}{ Adubação de base $\left(\mathrm{kg} \mathrm{ha}^{-1}\right)$} \\
\hline $\mathrm{N}$ & 49,4 & 49,4 & 49,4 \\
\hline $\mathrm{P}_{2} \mathrm{O}_{5}$ & 133 & 133 & 133 \\
\hline $\mathrm{K}_{2} \mathrm{O}$ & 38 & 38 & 38 \\
\hline \multicolumn{4}{|l|}{ Adubação $N$ de cobertura } \\
\hline V3 $\left(100 \mathrm{~kg} \mathrm{ha}^{-1}\right)$ & $02 / 11 / 2013$ & $11 / 10 / 2014$ & $16 / 10 / 2015$ \\
\hline V5 (100 kg ha $\left.{ }^{-1}\right)$ & $16 / 11 / 2013$ & $24 / 10 / 2014$ & $28 / 10 / 2015$ \\
\hline \multicolumn{4}{|l|}{ Aplicação dos tratamentos } \\
\hline V13 & $02 / 11 / 2013$ & $11 / 11 / 2014$ & $29 / 11 / 2015$ \\
\hline VT & $20 / 12 / 2013$ & $12 / 12 / 2014$ & $12 / 12 / 2015$ \\
\hline
\end{tabular}

se a correção do peso de parcela para $13 \%$ e calculou-se a produtividade em $\mathrm{kg} \mathrm{ha}^{-1}$. A MMG foi obtida através da contagem de 300 grãos e, em seguida, extrapolou-se este valor para 1.000 grãos. A porcentagem de grãos ardidos foi obtida através da seleção dos grãos considerados ardidos de uma amostra de 250 g. Após a seleção dos grãos ardidos, estes foram pesados e foi calculada a porcentagem.

Ainda da área útil da parcela, colheram-se dez espigas para a avaliação dos componentes de produtividade (número de fileiras por espiga, número de grãos por fileira, número de grãos por espiga). Estes foram obtidos através da contagem destas características para cada uma das dez espigas.

A homogeneidade das variâncias foi analisada através do teste de Bartlett pelo software Assistat. Uma vez comprovada a homogeneidade das variâncias, os dados foram submetidos à análise de variância e avaliados pelo Teste F. Quando os resultados revelaram significância a 5 ou $1 \%$ de probabilidade, as médias dos fatores qualitativos (anos e estádios) foram comparadas entre si pelo Teste de Tukey a 5\% de probabilidade e os valores dos fatores quantitativos (doses de polifosfato de amônio) foram submetidos a análise de regressão pelo software Sisvar. Buscouse o modelo que melhor expressasse a relação entre as variáveis. Com os valores das equações obtidas na análise de regressão, calculou-se também o ponto de máxima eficiência técnica (MET) (quando a resposta foi quadrática) através das fórmulas:

$$
x=-\frac{b}{2 a} \text { e } y=\frac{-b^{2}-4 a c}{4 a} \text {. }
$$

Por meio da equação de segundo grau gerada na análise de regressão, calculou-se a Dose de Máxima Eficiência Econômica (DMME).

\section{Resultados e Discussão}

Na Tabela 2, demonstra-se o resumo da análise de variância para as fontes de variação e variáveis 

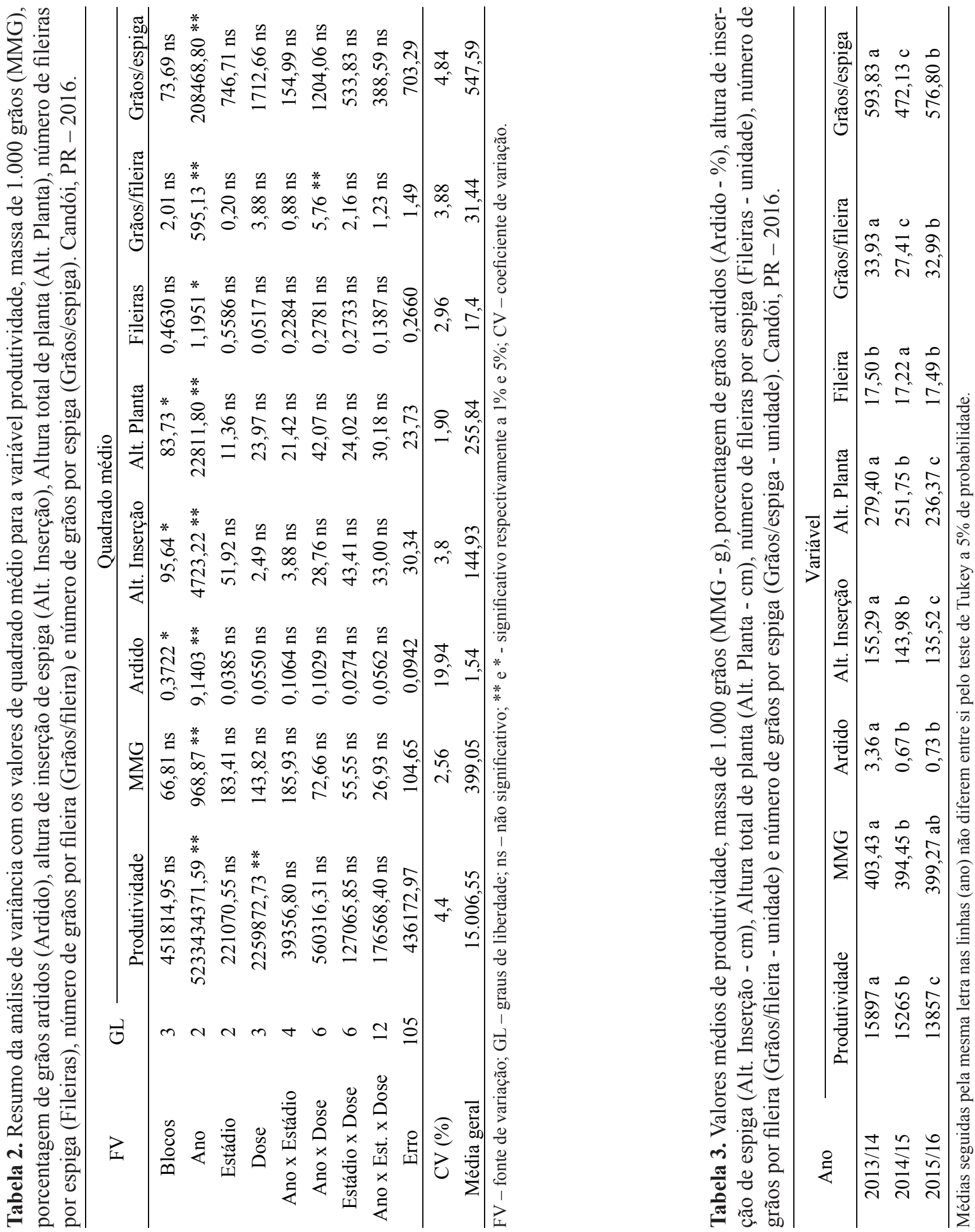
estudadas. Verifica-se que houve efeito de ano para todas as variáveis estudadas. Não se verificou efeito de estádio e, para a fonte de variação dose, constatouse apenas efeito sobre a produtividade. Verificou-se efeito da interação ano x dose apenas para a variável grãos por fileira.

As diferenças entre os anos para todas as variáveis estão demonstradas na Tabela 3; verifica-se que para todas as variáveis houve influência do ano, o que é um fato esperado, visto que há uma grande interferência do clima nessas características.

As diferenças entre os anos para todas as variáveis estão demonstradas na Tabela 3; verifica-se que para todas as variáveis houve influência do ano, o que é um fato esperado, visto que há uma grande interferência do clima nessas variáveis.

Como não se verificaram efeitos das interações dos tratamentos e nem efeito do estádio de aplicação, esses resultados permitem inferir que, independente do estádio e do ano de aplicação, haverá efeito positivo sobre a produtividade de grãos de milho em função do uso do polifosfato de amônio.
Além do mais, permite que produtores com diferentes tipos de tecnologia de aplicação (pulverizador de arrasto, autopropelido ou aviação agrícola) tenham a possibilidade de usufruir desta tecnologia. Na Figura 1, demonstra-se a influência do polifosfato de amônio na produtividade da cultura do milho. Verifica-se que, quando foi aplicado o polifosfato de amônio, houve acréscimo de produtividade quando comparado ao controle (dose $0 \mathrm{~L} \mathrm{ha}^{-1}$ ). A máxima produtividade foi obtida com a dose estimada de 9,54 $\mathrm{L} \mathrm{ha}^{-1}$ do produto, o que corresponde à aplicação de 5,08 e $1,51 \mathrm{~kg} \mathrm{ha}^{-1}$ de $\mathrm{P}_{2} \mathrm{O}_{5}$ e $\mathrm{N}$, respectivamente. A aplicação desta dose proporcionou um incremento de $570 \mathrm{~kg} \mathrm{ha}^{-1}$ na produtividade quando comparada à ausência de aplicação do polifosfato de amônio.

De acordo com Cobucci et al. (2010), é possível efetuar a aplicação de fósforo foliar na fase vegetativa como efeito estimulante ao crescimento da planta, com consequente aumento da absorção de nutrientes do solo, ou seja, aplicação de fósforo foliar pode aumentar a eficiência de utilização do fósforo presente no solo.

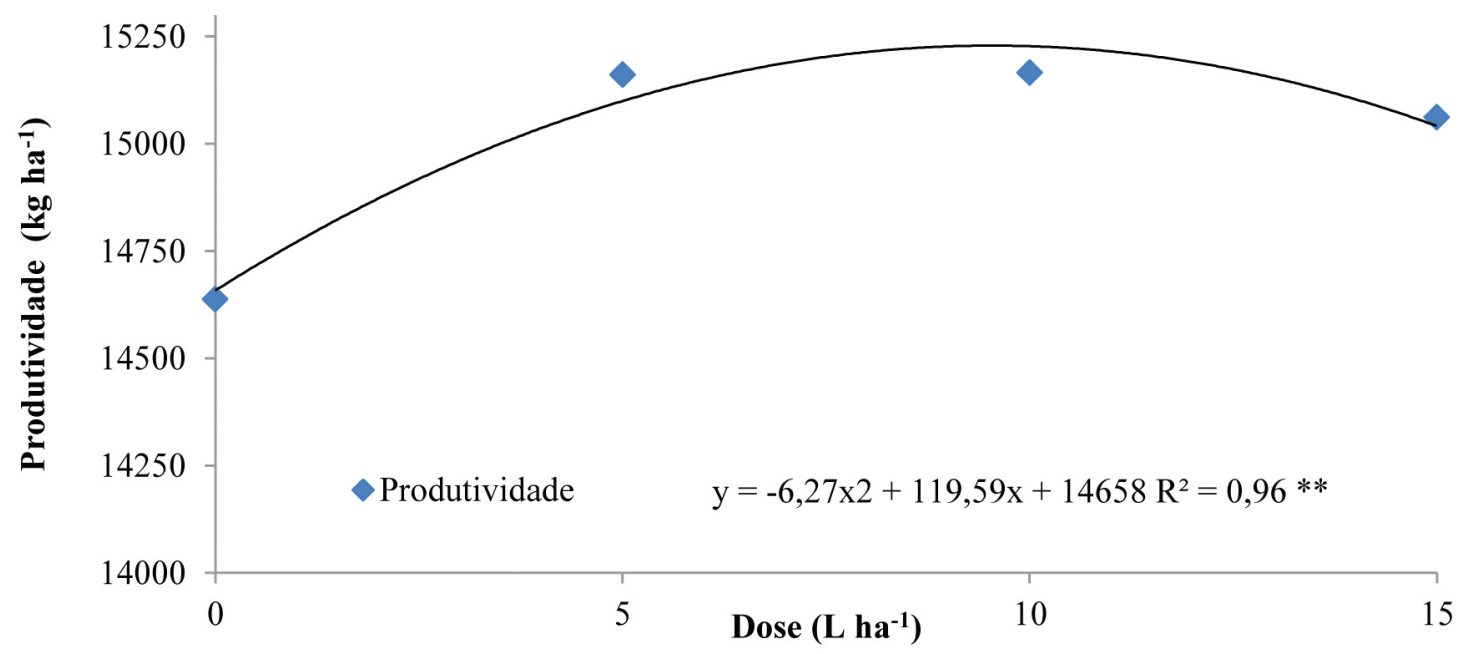

Figura 1. Produtividade da cultura do milho em função de doses crescentes de polifosfato de amônio na cultura do milho na média dos anos estudados. Candói, PR - 2016. ** significativo a 1\%. 
Os resultados positivos obtidos neste trabalho devido à aplicação de $\mathrm{N}$ e $\mathrm{P}$ via foliar concordam com Fageria et al. (2009), os quais relataram que a reposição dos nutrientes diretamente nas folhas poderia manter a taxa de fotossíntese por um tempo maior, refletindo-se possivelmente em maior produção de grãos nas culturas.

Ainda, deve ser discutida a influência do $\mathrm{N}$ no aumento da produtividade da cultura do milho. É impossível, com a aplicação de polifosfato de amônio, isolar o efeito do $\mathrm{N}$ e do P. Mesmo com a impossibilidade de isolamento, sabe-se que ambos os nutrientes apresentam influência positiva na produtividade da cultura. Segundo Deuner et al. (2008), a aplicação de $\mathrm{N}$ via foliar pode ser uma maneira eficiente para complementar o que é absorvido pelas raízes.

Também é importante observar o equilíbrio entre a adubação nitrogenada e a fosfatada, visto que desequilíbrios entre essas adubações podem causar sérios prejuízos para a produtividade da cultura. Segundo Nannetti (2001), há efeito sinérgico entre o uso de nitrogênio e o fósforo.

Porém, faz-se necessário considerar que a dose de máxima eficiência técnica não necessariamente apresenta viabilidade econômica. Assim, por meio da equação de segundo grau $\left(y=-6,27 x^{2}+119,59 x+\right.$ 14658) gerada na análise de regressão (os valores de $-6,27,119,59$ e 14.658 são respectivamente os valores de $a, b$ e $c$ da equação), calculou-se a Dose de Máxima Eficiência Econômica (DMME). A fórmula para o cálculo em questão é:

$\mathrm{DMEE}=((\mathrm{PP} / \mathrm{PG})-119,59) /(2 \times(-6,27))$

$\mathrm{DMME}=7,14 \mathrm{~L} \mathrm{ha}^{-1}$

onde: PP - Preço do produto - polifosfato de amônio $\left(\mathrm{R} \$ \mathrm{~L}^{-1}\right)$ e $\mathrm{PG}$ - Preço do grão de milho $\left(\mathrm{R} \$ \mathrm{~kg}^{-1}\right)$;

Para estes cálculos, assumiram-se o PP como $\mathrm{R} \$ 20,00$ e o PG como R\$ 0,67. O valor de PP foi obtido na empresa que produz o produto (Agrichem do Brasil) e o PG foi obtido por meio das médias dos preços pagos por este cereal em junho de 2016. Tendo em vista a diversidade de equipamentos para a aplicação dos produtos, o custo da aplicação não foi considerado nesse estudo.

Ainda, em função do valor de $c$ (equação gerada pela análise de regressão), calculou-se a produtividade máxima que a DMEE produziria; esse valor foi denominado de PMME (Produtividade de Máxima Eficiência Econômica). O PMME pode ser calculado pela fórmula abaixo:

PMME $=\left(\left(\mathrm{DMME}^{2}\right) \times(-6,27)\right)+(119,59 \times \mathrm{DMME})$ +14.658, logo:

PMME $\left.=\left(7,14^{2}\right) \times(-6,27)\right)+(119,59 \times 7,14)+14.658$ $\mathrm{PMME}=15.192 \mathrm{~kg} \mathrm{ha}^{-1}$

Por fim, em função dos valores obtidos de DMEE e PMEE, calculou-se o incremento de produtividade (IP) proporcionado pela aplicação da DMME. Logo, o incremento de produtividade pode ser calculado através da fórmula:

$\mathrm{IP}=\mathrm{PMME}-14.658$

Ao realizar a análise econômica, verificouse que a Dose de Máxima Eficiência Econômica (DMEE) poderia ser obtida por meio da aplicação de 7,14 L ha' ${ }^{-1}$ de polifosfato de amônio, o que corresponderia a um acréscimo de $534 \mathrm{~kg} \mathrm{ha}^{-1}$ na produtividade da cultura do milho. A DMEE corresponderia a uma aplicação de 3,80 e 1,13 kg ha-1 de $\mathrm{P}_{2} \mathrm{O}_{5}$ e $\mathrm{N}$, respectivamente.

É importante salientar que a Dose de Máxima Eficiência Econômica é variável em função do preço do polifosfato de amônio (produto comercial), bem como do preço de comercialização do milho. De modo que qualquer alteração no preço do produto ou do grão alterará a relação entre o polifosfato de amônio e milho. 
Tabela 4. Valores de número de grãos por fileira em função de doses crescentes de polifosfato de amônio aplicadas na cultura do milho nas safras 2013/14, 2014/15 e 2015/16. Candói, PR - 2016.

\begin{tabular}{|c|c|c|c|c|c|}
\hline \multirow{2}{*}{ Ano } & \multicolumn{4}{|c|}{ Dose $\left(\mathrm{L} \mathrm{ha}^{-1}\right)$} & \multirow{2}{*}{ Equação } \\
\hline & 0 & 5 & 10 & 15 & \\
\hline $2013 / 14$ & $33,94 \mathrm{a}$ & $33,90 \mathrm{a}$ & $33,93 \mathrm{a}$ & $33,93 \mathrm{a}$ & $y=0,0004 x^{2}-0,006 x+33,935 R^{2}=0,44 n s$ \\
\hline $2014 / 15$ & $27,80 \mathrm{~b}$ & $27,22 \mathrm{~b}$ & $27,67 \mathrm{c}$ & $26,98 \mathrm{~b}$ & $y=-0,0011 x^{2}-0,0237 x+27,692 R^{2}=0,47 n s$ \\
\hline $2015 / 16$ & $33,59 \mathrm{a}$ & $33,58 \mathrm{a}$ & $31,40 \mathrm{~b}$ & $33,39 \mathrm{a}$ & $\mathrm{y}=0,02 \mathrm{x}^{2}-0,3556 \mathrm{x}+33,907 \mathrm{R}^{2}=0,41 * *$ \\
\hline
\end{tabular}

Médias seguidas pela mesma letra nas linhas (ano) não diferem entre si; ns - não significativo; ** - significativo a 1\%.

Desta forma, sugere-se que, quando houver as variações discutidas anteriormente, seja calculada novamente a DMEE através da formula $D M E E=((P P /$ $P G)-119,59) /(2 \times 6,27)$, alterando apenas os valores de $P P$ e $P G$.

De acordo com a Tabela 4 , apenas para a safra de 2015/16 houve diferença estatística entre as doses aplicadas de polifosfato de amônio para a variável número de grãos por fileira.

Ainda nesta mesma tabela, verifica-se que, para todas as doses, o menor valor para esta variável foi obtido na safra de 2014/15, que diferiu estatisticamente dos valores obtidos para as demais safras. Diferenças significativas entre as doses foram verificadas unicamente na safra 2015/16.

A ausência de diferença estatística nos componentes de produtividade demonstra que o aumento de produtividade proporcionado pelo uso de polifosfato de amônio foi devido a pequenos aumentos em cada um dos componentes de produtividade, sendo que esses pequenos acréscimos individuais não diferiram entre si estatisticamente.

\section{Conclusões}

- Houve influência positiva das doses de polifosfato de amônio estudadas na produtividade da cultura do milho. O máximo incremento de produtividade $\left(570 \mathrm{~kg} \mathrm{ha}^{-1}\right)$ foi obtido com a aplicação de 5,08 e $1,51 \mathrm{~kg} \mathrm{ha}^{-1}$ de $\mathrm{P}_{2} \mathrm{O}_{5}$ e $\mathrm{N}$, respectivamente, o que corresponde a 9,54 $\mathrm{L} \mathrm{ha}^{-1}$ de polifosfato de amônio. A resposta positiva independe do ano e do estádio de aplicação.

- O uso de polifosfato de amônio apresenta viabilidade econômica, sendo que o incremento de produtividade (em função da DMEE) foi de $534 \mathrm{~kg}$ $\mathrm{ha}^{-1}$ e foi obtido por meio da aplicação de $7,14 \mathrm{~L} \mathrm{ha}^{-1}$ de polifosfato de amônio, ou seja, 3,80 e 1,13 $\mathrm{kg} \mathrm{ha}^{-1}$ de $\mathrm{P}_{2} \mathrm{O}_{5}$ e $\mathrm{N}$, respectivamente.

- A aplicação do polifosfato de amônio não influenciou estatisticamente os componentes de produtividade estudados.

\section{Referências}

BROGGI, F.; OLIVEIRA, A. C.; FREIRE, F. J.; OLIVEIRA, E. C. A.; ROCHA, A. T.; FREIRE, M. B. G. S. Níveis críticos de fósforo em milho cultivado em solos de diferentes mineralogias. Revista Caatinga, Mossoró, v. 27, n. 4, p. 164-170, 2014.

COBUCCI, T.; PAIVA LIMA, D. A.; KLUTHCOUSKI, J.; OLIVEIRA, P.; NASCENTE, A. S. Aumento da eficiência de utilização de fósforo do solo em razão de aplicações foliares do nutriente. Scientia Agrária, Curitiba, v. 13, n. 6, p. 367-371, 2010.

DEUNER, S.; NASCIMENTO, R.; FERREIRA, L. S.; BADINELLI, G.; KERBER, R. S. Adubação foliar e via solo de nitrogênio em plantas de milho em fase inicial de desenvolvimento. Ciência e Agrotecnologia, Lavras, 
32, n. 5, p. 1359-1365, 2008.

DOI: $10.1590 / \mathrm{S} 1413-70542008000500001$.

FAGERIA, N. K.; BARBOSA FILHO, M. P.; MOREIRA, A.; GUIMARÃES, C. M. Foliar fertilization of crop plants. Journal of Plant Nutrition, New York, v. 32, n. 6, p. 1044-1064, 2009. DOI: 10.1080/01904160902872826.

FANCELLI, A. L. Milho. In: PROCHNOW, L. I.; CASARIN, V.; STIPP, S. R. (Ed.). Boas práticas para uso eficiente de fertilizantes. Piracicaba: IPNI, 2010. v. 3, p. 39-93.

LEE, R. B.; PURVES, J. V.; RATCLIFFER, R. G.; SAKER, L. R. Nitrogen assimilation and the control of ammonium and nitrate absorption by maize roots. Journal of Experimental Botany, Oxford, v. 43, n. 11, p. 1385-1396, 1992. DOI: $10.1093 / \mathrm{jxb} / 43.11 .1385$.

MEIRA, F. A.; BUZETTI, S.; ANDREOTTI, M.; ARF, O.; SÁ, M. E.; ANDRADE, J. A. C. Fontes e épocas de aplicação do nitrogênio na cultura do milho irrigado. Semina: Ciências Agrárias, Londrina, v. 30, n. 2, p. 275-284, 2009.

NANNETTI, D. C. Nitrogênio e potássio aplicados via fertirrigação na produção, nutrição e pós-colheita do pimentão. 2001. 184 f. Dissertação (Mestrado) - Universidade Federal de Lavras, Lavras, 2001.

NOVAIS, R. F.; SMYTH, T. J.; NUNES, F. N. Fósforo. In: NOVAIS, R. F.; ALVAREZ V., H. V.; BARROS, N. F.; FONTES, R. L. F.; CANTARUTTI, R. B.; NEVES, J. C. L. (Ed.). Fertilidade do solo. Viçosa, MG: Sociedade Brasileira de Ciência do Solo, 2007. p. 471-550.
OLIVEIRA, P.; NASCENTE, A. S.; KLUTHCOUSKI, J.; PORTES, T. A. Crescimento e produtividade de milho em função da cultura antecessora. Pesquisa Agropecuária Tropical, Goiânia, v. 43, n. 3, p. 239-246, 2013. DOI: $10.1590 / \mathrm{S} 1983-40632013000300005$.

PELÁ, A.; RODRIGUES, M. S.; SANTANA, J. S.; TEIXIERA, I. R. Fontes de fósforo para adubação foliar na cultura do feijoeiro. Scientia Agraria, Curitiba, v. 10, n. 4, p. 313-318, 2009.

REZENDE, P. M.; GRIS, C. F.; CARVALHO, J. G.; GOMES, L. L.; BOTTINO, L. Adubação foliar: I. Épocas de aplicação de fósforo na cultura da soja. Ciência e Agrotecnologia, Lavras, v, 29, n. 6, p. 1105-1111, nov./dez. 2005. DOI: $10.1590 / \mathrm{S} 1413-70542005000600001$.

SILVA, P. R. C. Processo de produção de adubos foliares. Salvador: Serviço Brasileiro de Respostas Técnicas, 2006. 5 p.

SOUTO, J. S.; OLIVEIRA, F. T.; GOMES, M. M. S.; NASCIMENTO, J. P.; SOUTO, P. C. Efeito da aplicação de fósforo no desenvolvimento de plantas de feijão guandu (Cajanus cajan (L) Millsp). Revista Verde, Mossoró, v. 4, n. 1, p. 135-140, 2009.

TAIZ, L.; ZEIGER, E. Fisiologia vegetal. 4. ed. Porto Alegre: Artmed, 2009. 848 p. 